Article

\title{
Forest Biomass for Energy Production: Perceptions of State Forestry Professionals from China and India
}

\section{Pradipta Halder}

School of Forest Sciences, University of Eastern Finland, Yliopistokatu 7, Joensuu 80101, Finland; E-Mail: pradipta.halder@uef.fi or pradipta.halder@gmail.com; Tel.: +358-40-747-0711

External Editor: Andreas Manz

Received: 14 July 2014; in revised form: 12 September 2014 / Accepted: 8 October 2014 /

Published: 16 October 2014

\begin{abstract}
This study investigated perceptions of a group of Chinese and Indian state forestry professionals (SFPs) related to the potential benefits and challenges of developing forest-based bioenergy projects (FBPs) in their countries. A total of 110 SFPs participated in the study (55 from each country). The results showed that the SFPs widely agreed upon the potential economic and ecological benefits from developing FBPs in their countries. The economic benefits of job creation and additional income to forest departments were the two most accepted benefits by the SFPs. Two potential challenges of developing FBPsnamely, the lack of suitable technologies and the absence of supportive policies-were considered the most significant by the SFPs. Principal component analysis revealed three key dimensions (ecological, economic and social) of the SFPs' perceptions of FBPs. The findings from the study imply that in order to become viable, the development of FBPs in these two countries must put emphasis on the sustainability aspects by addressing the environmental, economic and societal elements of FBPs. In addition, framing supportive policies, the development of technologies and building infrastructure for FBPs are needed for their successful implementation in China and India.
\end{abstract}

Keywords: bioenergy; forest; perceptions; state forestry professionals; China; India 


\section{Introduction}

\subsection{Bioenergy Sector in China and India}

China and India are the second and fifth largest primary energy consumers in the world, respectively [1]. At the same time, both are highly dependent on fossil fuels, mainly domestic reserves of coal and imported oil, and this status quo will likely remain unchanged for at least the next two decades [1]. China, however, has made significant progress in investing in renewable energy technologies. The country is now one of the leading countries in the world in terms of investing in renewable energy technologies, which amounted to an estimated USD 52 billion in 2011 [2]. India has also made a notable stride in RE investment, mostly driven by the National Solar Mission, which amounted to an estimated USD 12 billion in 2011, and the country was among the fastest growing renewable energy markets in the world [2]. Nevertheless, a large disparity is apparent between the two countries when it comes to their populations' access to modern energy services, as well as dependency on bioenergy. The International Energy Agency [1] has estimated that about one-quarter of India's population is living without access to electricity, and about $10 \%$ of Indians will remain in such a condition until 2030. The report has also estimated that almost half of Indians ( $c a .735$ million people) will remain dependent on biomass fuels for cooking until 2030. In contrast, energy experts estimate that China will achieve electricity access for all her population by 2030 ; however, about $17 \%$ of the population will remain without clean cooking facilities by that time [1]. It is evident from these projections that people's dependency on solid biomass for cooking and heating will remain significant in India, especially in the rural areas, whereas China will be able to gradually reduce such dependency in the coming years. Nevertheless, the importance of biomass for providing transport fuels (e.g., ethanol, biodiesel and biogas) is expected to increase in both China and India, due to their national biofuel polices and targets, though such a similar trend cannot be projected for wood-based heat and power generation in these two countries.

National policies on biofuels started emerging in China and India in the beginning of the last decade. The first biofuel policy appeared in China in 2001 through the Special Development Plan for Denatured Fuel Ethanol and the First Five-Year Plan for Bioethanol, which supported experiments with bioethanol production from stale grain stocks [3]. The Renewable Energy Law of China came into effect in 2006, which affirmed China's commitment towards using biomass-based fuels [3]. In 2007, the Chinese Government launched the Middle and Long-Term Development Plan for China's Renewable Energy, and it aimed to address the concerns over potential food vs. fuel conflicts in China's context by mandating the production of ethanol only from non-grain-based feedstock. The Plan also set a target for producing 10 million tons of ethanol by 2020 [4]. On the contrary, biodiesel policies in China are less developed compared to the bioethanol policies [3], even though the Middle and Long-Term Development Plan for China's Renewable Energy of 2007 set a target of producing two million tons of biodiesel by 2020 [4]. The Development Plan for China's Bio-forestry Businesses was released in 2007 by the State Forestry Administration (SFA), and the Plan set a target of bringing 13 million ha of land under energy tree plantations by 2020 to meet the targets for biodiesel production [3].

The Government of India (GoI) adopted a National Policy on Biofuels (NPB) in 2009, which set a target of achieving a 20\% blend of biofuels with both gasoline and diesel by 2017 [5]. However, long 
before the NPB came into being, the GoI launched an Ethanol Blending Program (EBP) in 2003 and mandated a 5\% ethanol (produced from sugarcane molasses) blend with gasoline. A National Biodiesel Mission (NBM) was established in 2007 after identifying Jatropha (Jatropha curcas) as the most suitable tree-borne oilseed for biodiesel production in India. The Planning Commission of India set a target of bringing 11 to 13 million ha of land, particularly degraded and wastelands, under Jatropha plantations by 2012. One of the main objectives of all of these policy initiatives was to avoid any potential conflicts between the production of food and biofuels, and therefore, non-grain-based feedstock was always encouraged for biofuels production in India. However, the target under the EBP has not been achieved due to highly fluctuating sugarcane production in India, whereas the NBM has progressed slowly due to the failure in Jatropha plantations across the country [6]. There is no recent information available related to the achievements in the NPB, and from observing the failures in both the EBP and NBM, it can be assumed that the blending target under the NPB has not been met due to similar reasons that affected the other two programs [6,7].

In comparison to liquid biofuels policies, the forest-based bioenergy sector is yet to gain momentum in China and India. In China, firewood is traditionally used by rural households, though its importance in the country is going to decline in the future [8]. However, the development of a modern forest-based bioenergy sector fits well within the national strategies for $\mathrm{CO}_{2}$ reduction and rural development, while major challenges are emerging from the unstable feedstock supply, inadequate research and development and a lack of investment in forest-based bioenergy industries in China [8]. Unlike China, a large number of people in India depend on forest and agricultural biomasses for cooking and heating, and yet, there is no specific policy being initiated by the GoI to improve the supply of forest biomass for meeting the fuel wood demand of the people. The most recent NPB does not provide any clear guidance for this aspect, and thus, it is difficult to anticipate the future developments in the forest-based bioenergy sector in India [9]. The Ministry of New and Renewable Energy of the GoI has initiated a biomass-based power generation program from bagasse produced in sugar mills [10], and it once again overlooked the potential use of forest biomass for meeting the heat and electricity demand of a sizeable portion of the population. Recent estimates show that about $40 \%$ of the wasteland areas in the country are available for forestation, and about 14 million ha are potentially suitable for the cultivation of bioenergy feedstock [11]. However, a major portion of these wastelands may have already been occupied by landless and indigenous peoples for habitation, grazing and agricultural purposes [6].

\subsection{Experts' Perceptions of Energy Production from Forest Biomass}

There has been a growing number of studies that analyzed various stakeholders' (e.g., biomass producers, general public, experts, bioenergy industry and students) perceptions and attitudes related to bioenergy in different parts of the world (see [12]). However, for this study, only those that focused on bioenergy experts are presented. One such study for this purpose is the study by Magar et al. [13], who conducted a survey among bioenergy experts in the European Union. The study revealed that the European experts perceived bioenergy quite positively, and at the same time, they emphasized the need to improve the awareness of bioenergy in Europe. Those experts also strongly perceived that certification of bioenergy would be necessary in Europe to promote its trade. In another study, mixed perceptions of bioenergy appeared among Brazilian bioenergy experts. They recognized the benefits of producing 
ethanol from sugar cane, such as the creation of new jobs and the increase in energy security for Brazil; however, they also perceived that ethanol production in Brazil created various social and ecological problems, such as income inequality and destruction of tropical rainforests [14]. Somehow, similar perceptions of bioenergy were detectable among the experts in the United States (U.S.), who perceived that bioenergy production could provide economic benefits and improve energy security in the country, while it could also lead to potential conflicts between different uses of biomass $[15,16]$. In a comparative study involving bioenergy experts from Brazil, Sweden and the U.S., Hultman et al. [17] found that those experts perceived that the bioenergy industry in their countries became successful due to policy support for bioenergy technologies, as well as pre-existing favorable socio-technical infrastructure.

The studies that have analyzed experts' perceptions of energy production from forest biomass are not voluminous in number, however. In this direction, a study by Dwivedi and Alavalapati [18] explored perceptions of representatives from non-governmental organizations (NGOs), industry, government and academia related to forest-based bioenergy development in the U.S. The study found that the NGOs perceived forest-based bioenergy development as an important opportunity for rural development, and government officials perceived bioenergy to be important for addressing energy security in the U.S. This study also revealed that the representatives from academia perceived solar and wind power as the major threats to the development of bioenergy projects, whereas the industrial representatives perceived the lack of advanced technology as a major weakness for forest-based bioenergy development in the U.S. However, in general, strong positive perceptions of forest-based bioenergy were found among the U.S. experts. Mayfield et al. [19] revealed from another experts-based study in the U.S. that the experts perceived that improvement of marketing, infrastructure, community engagement, collaboration and education would be essential to promote large-scale forest biomass-based energy production in the southern U.S. states.

Apart from the studies in Europe and North America, there have been a few studies in recent years on experts' perceptions of energy production from forest biomass in Asian countries. In this regard, Qu et al. [20] conducted a study among a group of Chinese academicians to explore their perceptions of developing forest-based bioenergy projects (FBPs) in China. Their study found that the academic professionals were highly concerned over the challenges to the development of FBPs in China, though they perceived that such projects could bring a number of socio-economic benefits to their country. In another study, Qu et al. [21] revealed that the Chinese forestry professionals and provincial forestry program managers perceived that the development of FBPs would need strong collaboration between the public and private sectors to increase its potential as a viable option for China. Gautam et al. [22] conducted a study among a group of Nepalese state forestry professionals (SFPs) and found strong positive perceptions of FBPs among the Nepalese SFPs, as they perceived that such projects would be able to bring economic, environmental and social benefits to Nepal. In an Indian context, there have been a few techno-economic studies regarding the opportunities and challenges concerning bioenergy development; however, none have focused on FBPs, perhaps due to the reason that conversion technologies for second generation biofuels have not been developed in the country [23]. Most recently, Halder et al. [9] conducted a study among a group of professionals working in the Indian Forest Service (IFS) to explore their perceptions of developing FBPs in India. Their study found that while the IFS professionals perceived that such projects could create jobs and income, they were also concerned over 
the lack of public awareness and political support, as well as the lack of suitable technologies for such projects in India.

Forests cover about one-fifth ( $c a .68$ million ha) of the land area in India, and more than $90 \%$ of this forest is publicly owned. The Ministry of Environment and Forests (MoEF) under the GoI is the nodal agency for managing public forests in India, and the IFS professionals working under the MoEF play an important role in implementing the governmental policies in forest areas under their jurisdictions. Similarly, the SFA, a public organization, is responsible for managing China's vast forest areas (ca. 195 million ha), which cover around 20\% of the country's total land area [24]. Professionals working under the SFA play a key role in forest management and decision-making in China, and they are also responsible for improving public perceptions of the increased use of bioenergy in China [21]. It can be said that these SFPs are important informants in both countries to provide suggestions to the policy makers for developing a forest-based bioenergy sector. They can combine their scientific knowledge and experiences from the field, which would be important for developing FBPs in these countries. However, to the best of our knowledge, there is no study that has compared Chinese and Indian SFPs' perceptions of the potential benefits and challenges of developing FBPs in their respective countries.

\subsection{Aims of the Study}

The study, based on the above discussions, aimed to analyze SFPs' perceptions of the potential benefits and challenges of developing FBPs in China and India. The study also attempted to reveal the key dimensions of their perceptions of FBPs. Through the findings, the study attempted to raise awareness of the policy makers and bioenergy developers about the key issues that they need to take into account for developing sustainable FBPs in China and India.

\section{Methodology}

\subsection{Survey Instrument Design and Data Collection}

The present study was part of an international comparative research that aimed to analyze perceptions of Chinese and Indian SFPs regarding potential benefits and challenges of developing FBPs in their countries. Results from the India-specific study have been published in Halder et al. [9], and therefore, this study will only present the results of the comparative analysis between the two countries. Data were collected from a group of Indian SFPs when they participated in a forestry training program in Finland in 2010. Data from the Chinese SFPs were collected in 2011 when they participated in two training programs in China to enhance their skills for managing forests sustainably. The Indian SFPs who participated in the training program in Finland were selected by the MoEF (GoI), and the Chinese participants were selected by the SFA, China. The questionnaire used for this study consisted of two sections with closed-ended items. The first section was comprised of questions related to the SFPs' background profiles (e.g., age, gender, career length and educational qualifications). A five-point Likert scale (strongly agree, agree, neutral, disagree, strongly disagree) consisting of 14 items was part of the second section. There were six items that measured the SFPs' perceptions of the potential benefits of FBPs, while eight items measured their perceptions of the potential challenges to such projects in their 
countries. The items on the Likert scale were designed based on a literature review on stakeholders' perceptions of bioenergy and also by consulting a number of bioenergy experts in China and India.

The questionnaire for the Indian participants was prepared only in English, while it was translated into Chinese by a researcher from China for the Chinese participants. A bioenergy expert in China validated the translation to maintain the compatibility and comparability of both the questionnaires. The Chinese researcher distributed the questionnaires to the SFPs during their training sessions and collected them upon completion of the session. The Chinese researcher was responsible for entering the data into a statistical software package. Since there were no open-ended questions in the questionnaire, back translation into English from Chinese was not required. The survey among the Indian participants was carried out in a similar way in Finland. A researcher from Finland was responsible for conducting the survey among the Indian participants. It took approximately 30 minutes for the respondents to complete the survey. In both China and Finland, the survey response rate was $100 \%$. The questionnaire can be obtained from the corresponding author upon request.

\subsection{Data and Statistical Analysis}

There was a total of 110 SFPs who participated in the survey: 55 from China (mean age $=47$ years, $\mathrm{SD}=7.5$ ) and 55 from India (mean age $=49$ years, $\mathrm{SD}=5.8$ ). Around $85 \%$ of the Chinese participants and all of the Indian participants were male. In terms of educational qualifications, the majority of the Chinese participants had a bachelor's degree, while the majority of the Indian participants had a master's degree. The majority of the Indian participants were working for 10-20 years in the forestry service, while the majority of the Chinese participants were working for more than 20 years in their forestry profession. The items on the Likert scale were checked for their internal consistencies with Cronbach's alpha $(\alpha)$, and the optimal level of mean inter-item correlation (MIC) was also calculated. The reliability of the six items that analyzed the SFPs' perceptions of the potential benefits of FBPs was $\alpha=0.77$ and $M I C=0.36$ (China: $\alpha=0.75, M I C=0.32$; India: $\alpha=0.81, M I C=0.42$ ). The reliability of the eight items that measured their perceptions of the potential challenges to FBPs was $\alpha=0.72$ and $M I C=0.25$ (China: $\alpha=0.76, M I C=0.28$; India: $\alpha=0.58, M I C=0.16$ ). Cronbach's alpha value equal to or greater than 0.70 is generally considered an acceptable level of internal consistency for items on a Likert scale [25], and the acceptable range of $M I C$ is 0.20 to 0.40 [26]. The study used descriptive statistics, $t$-tests and principal component analysis to analyze the structure and relationships of the Chinese and Indian SFPs' perceptions of FBPs. Data analysis was conducted by the IBM SPSS 19 statistical software package.

\section{Results}

\subsection{SFPS' Perceptions of the Potential Benefits from FBPs in China and India}

Perceptions of the Chinese and Indian SFPs related to the potential benefits from developing FBPs in their countries are presented in Table 1 from the pooled data. It appeared that they perceived the creation of new jobs and additional income to their forest departments as the two benefits with the most potential for developing FBPs. The positive impacts of FBPs on reducing soil erosion and land degradation were also perceived quite strongly by the respondents from both countries. Similarly, the majority of the respondents ( $\mathrm{ca} .78 \%$ ) perceived that energy security could be achieved through the development of 
FBPs in their countries. About $62 \%$ of the SFPs agreed that biomass harvesting from forests for energy production could improve the health of forests in their countries; however, a statistically significant difference $(t(97)=3.42, p<0.01)$ appeared between the respondents in the two countries, and the effect size was moderate (Cohen's $d=0.66$ ). It appeared that the Chinese SFPs were more positive (mean = $3.33, \mathrm{SD}=1.06$ ) than the Indians (mean $=3.95, \mathrm{SD}=0.78$ ) related to this particular notion of benefit from FBPs.

Table 1. State forestry professionals' perceptions of the potential benefits of forest-based bioenergy projects in China and India.

\begin{tabular}{|c|c|c|c|c|}
\hline \multirow{2}{*}{ Potential Benefits } & \multirow{2}{*}{ Agreement } & \multirow{2}{*}{ Disagreement } & \multirow{2}{*}{ Neutral } & \multirow{2}{*}{$\begin{array}{c}\text { Country-Wise Difference } \\
t \text {-Test }(p \text {-Values }) \\
\end{array}$} \\
\hline & & & & \\
\hline $\begin{array}{l}\text { Bioenergy production from forests will create } \\
\text { new jobs }(\text { Mean }=4.32, \mathrm{SD}=0.69)\end{array}$ & $94 \%$ & $4 \%$ & $2 \%$ & 0.139 \\
\hline $\begin{array}{l}\text { Biomass extraction for energy production will be an } \\
\text { additional source of income from forests to the forest } \\
\text { department (Mean }=4.08, \mathrm{SD}=0.84)\end{array}$ & $86 \%$ & $8 \%$ & $6 \%$ & 0.902 \\
\hline $\begin{array}{l}\text { Energy wood plantations will reduce soil erosion } \\
(\text { Mean }=4.16, \mathrm{SD}=0.78)\end{array}$ & $82 \%$ & $3 \%$ & $15 \%$ & 0.499 \\
\hline $\begin{array}{l}\text { Energy wood plantations will reduce land degradation } \\
(\text { Mean }=4.06, \mathrm{SD}=0.84)\end{array}$ & $81 \%$ & $6 \%$ & $13 \%$ & 0.108 \\
\hline $\begin{array}{l}\text { Energy production from forest biomass will greatly help to } \\
\text { achieve energy security }(\text { Mean }=3.99, \mathrm{SD}=0.92)\end{array}$ & $78 \%$ & $9 \%$ & $13 \%$ & 0.355 \\
\hline $\begin{array}{l}\text { Harvesting biomass from forests for energy production can } \\
\text { improve the health of forests (Mean }=3.64, \mathrm{SD}=0.98 \text { ) }\end{array}$ & $62 \%$ & $16 \%$ & $22 \%$ & $0.001 *$ \\
\hline
\end{tabular}

Notes: Agreement has been defined as strongly agree plus agree; disagreement as strongly disagree plus disagree. The coding was done as strongly agree $=5$, agree $=4$, neutral $=3$, disagree $=2$ and strongly disagree $=1$. $* p<0.05$.

\subsection{SFPs' Perceptions of the Potential Challenges against Developing FBPs in China and India}

It appeared from the pooled data that lack of suitable technologies and supportive policies were perceived by the SFPs as the two most important challenges against the development of FBPs in China and India (Table 2). Statistically significant differences $(t(107)=4.32, p<0.01)$ emerged between the SFPs in the two countries regarding the issue of political support for FBPs with a large effect size (Cohen's $d=0.86$ ). The Chinese SFPs appeared to be more concerned (mean $=4.45, \mathrm{SD}=0.63$ ) over that particular challenge compared to their Indian counterparts (mean $=3.81, \mathrm{SD}=0.89$ ). Lack of infrastructure and the high level of investment required for developing FBPs appeared as the other two widely perceived challenges against developing FBPs in China and India. Statistically significant differences were found between the SFPs in the two counties related to the issue of lack of infrastructure $(t(104)=2.80, p<0.01)$ and high level of investment $(t(108)=2.27, p<0.05)$ with moderate effect sizes (Cohen's $d=0.53$ ) and (Cohen's $d=0.43$ ), respectively. The Chinese respondents perceived both the challenges more strongly compared to the Indian SFPs.

The majority of the SFPs also perceived that low public awareness and low public acceptability would be the other two potential challenges against the development of FBPs in their countries, and a statistically 
significant difference appeared $(t(108)=2.00, p<0.05)$ between the SFPs concerning the latter with a small effect size (Cohen's $d=0.38$ ). The Chinese SFPs appeared to be more concerned (mean $=3.80$, $\mathrm{SD}=0.93$ ) over the issue of low public acceptability than the Indian SFPs (mean $=3.45, \mathrm{SD}=0.88$ ), whereas the Indian SFPs were more in agreement (mean $=3.73, \mathrm{SD}=0.83$ ) with the low public awareness than their Chinese counterparts (mean $=3.62, \mathrm{SD}=0.95$ ). Although no such strong agreements appeared, statistically significant differences emerged with moderate effect sizes among the SFPs between the two countries related to their perceptions of the two other potential challenges against developing FBPs - namely, the lack of information among SFPs related to such projects $(t(108)=2.71, p<0.01$, Cohen's $d=0.51)$ and the cost competitiveness of FBPs compared to the other renewable energy projects $(t(107)=2.93, p<0.05$, Cohen's $d=0.56)$. It appeared that the Chinese SFPs were more in agreement with both of these two challenges compared to their Indian counterparts.

Table 2. State forestry professionals' perceptions of the potential challenges against developing forest-based bioenergy projects in China and India.

\begin{tabular}{|c|c|c|c|c|}
\hline \multirow{2}{*}{ Challenges } & \multirow{2}{*}{ Agreement } & \multirow{2}{*}{ Disagreement } & \multirow{2}{*}{ Neutral } & \multirow{2}{*}{$\begin{array}{c}\text { Country-Wise Difference } \\
t \text {-Test }(p \text {-Values }) \\
\end{array}$} \\
\hline & & & & \\
\hline $\begin{array}{l}\text { Technology has not yet been developed that allows the } \\
\text { efficient use of forest biomass as a source of bioenergy } \\
(\text { Mean }=4.05, \mathrm{SD}=0.78)\end{array}$ & $85 \%$ & $6 \%$ & $9 \%$ & 0.114 \\
\hline $\begin{array}{l}\text { A lack of policy support will limit the large scale use } \\
\text { of forest biomass for bioenergy production (Mean }=4.14 \text {, } \\
\mathrm{SD}=0.83 \text { ) }\end{array}$ & $80 \%$ & $5 \%$ & $15 \%$ & $0.000 *$ \\
\hline $\begin{array}{l}\text { Lack of infrastructure will limit the large-scale use } \\
\text { of forest biomass for bioenergy production (Mean }=3.74 \text {, } \\
\mathrm{SD}=0.85 \text { ) }\end{array}$ & $72 \%$ & $12 \%$ & $16 \%$ & $0.006 *$ \\
\hline $\begin{array}{l}\text { Large-scale use of forest biomass for bioenergy } \\
\text { production requires too high levels of investment from } \\
\text { the state }(\text { Mean }=3.82, \mathrm{SD}=0.94)\end{array}$ & $71 \%$ & $13 \%$ & $16 \%$ & $0.025 *$ \\
\hline $\begin{array}{l}\text { Low public awareness will limit the large-scale use } \\
\text { of forest biomass for bioenergy production (Mean }=3.67 \text {, } \\
\mathrm{SD}=0.89 \text { ) }\end{array}$ & $69 \%$ & $14 \%$ & $17 \%$ & 0.523 \\
\hline $\begin{array}{l}\text { Low public acceptability will limit the large-scale use } \\
\text { of forest biomass for bioenergy production (Mean }=3.63 \text {, } \\
\mathrm{SD}=0.92 \text { ) }\end{array}$ & $67 \%$ & $15 \%$ & $18 \%$ & $0.048 *$ \\
\hline $\begin{array}{l}\text { Officers working for the state lack information for } \\
\text { assisting in the development of the large-scale use of } \\
\text { forest biomass for bioenergy production (Mean }=3.38 \text {, } \\
\mathrm{SD}=1.01 \text { ) }\end{array}$ & $51 \%$ & $25 \%$ & $24 \%$ & $0.008 *$ \\
\hline $\begin{array}{l}\text { Bioenergy projects based on forest biomass are more } \\
\text { expensive compared to other renewable energy projects } \\
(\text { Mean }=3.21, \mathrm{SD}=0.97)\end{array}$ & $43 \%$ & $28 \%$ & $29 \%$ & $0.004 *$ \\
\hline
\end{tabular}

Notes: Agreement has been defined as strongly agree plus agree; disagreement as strongly disagree plus disagree. The coding was done as strongly agree $=5$, agree $=4$, neutral $=3$, disagree $=2$ and strongly disagree $=1 . * p<0.05$.

\subsection{Key Dimensions of the SFP' Perceptions of FBPs}

Principal component analysis (PCA) was conducted to reveal the key dimensions of the SFPs' perceptions of FBPs in China and India, and the PCA from the pooled data revealed three key 
dimensions, which explained $75 \%$ of the variation in the data (Table 3). The first dimension appeared to be an ecological dimension, which consisted of two of the potential benefits of FBPs - the reduction in both land degradation and soil erosion - and this dimension accounted for $26 \%$ of the variation in the data. The second dimension denoted economic aspects that included items on the potential benefits of FBPs, like the creation of jobs, income to the forest department and improving energy security. This dimension also accounted for $26 \%$ of the variation in the data. The third key dimension was a social dimension that consisted of items related to public acceptability and awareness of FBPs, and it explained $23 \%$ of the variation in the data. The reliability check with the three key dimensions showed an acceptable level of internal consistency, as the values of Cronbach's $\alpha$ ranged from 0.71 to 0.86 . However, variability emerged in the internal consistency of these three key dimensions between the two countries. It appeared that in China, the social and ecological dimensions were more consistent than the economic dimension (Cronbach's $\alpha$ for social $=0.87$, ecological $=0.85$ and economic $=0.47$ ). In India, both ecological and economic dimensions appeared to be more consistent than the social dimension $($ Cronbach's $\alpha$ for ecological $=0.87$, economic $=0.85$ and social $=0.62)$.

Table 3. Key dimensions of the Chinese and Indian forestry professionals' perceptions of forest-based bioenergy projects (pooled data).

\begin{tabular}{lccc}
\hline & \multicolumn{3}{c}{ Loadings on the Key Dimensions } \\
\cline { 2 - 4 } Items on Potential Benefits and Barriers & $\begin{array}{c}\text { Ecological } \\
\boldsymbol{\alpha}=\mathbf{0 . 8 6}\end{array}$ & $\begin{array}{c}\text { Economic } \\
\boldsymbol{\alpha}=\mathbf{0 . 7 1}\end{array}$ & $\begin{array}{c}\text { Social } \\
\boldsymbol{\alpha}=\mathbf{0 . 7 5}\end{array}$ \\
\hline Energy wood plantations will reduce land degradation & $\mathbf{0 . 9 2 0}$ & 0.160 & -0.013 \\
\hline Energy wood plantations will reduce soil erosion & $\mathbf{0 . 9 1 4}$ & 0.129 & 0.092 \\
\hline $\begin{array}{l}\text { Biomass extraction for energy production will be an additional } \\
\text { source of income from forests to the forest department }\end{array}$ & 0.173 & $\mathbf{0 . 7 8 9}$ & -0.042 \\
\hline Bioenergy production from forests will create new jobs & -0.073 & $\mathbf{0 . 7 6 0}$ & 0.238 \\
\hline $\begin{array}{l}\text { Energy production from forest biomass will greatly help to } \\
\text { achieve energy security }\end{array}$ & 0.275 & $\mathbf{0 . 7 4 4}$ & -0.021 \\
\hline $\begin{array}{l}\text { Low public acceptability will limit the large-scale use of forest } \\
\text { biomass for bioenergy production }\end{array}$ & -0.079 & 0.044 & $\mathbf{0 . 8 9 2}$ \\
\hline $\begin{array}{l}\text { Low public awareness will limit the large-scale use of forest } \\
\text { biomass for bioenergy production }\end{array}$ & -0.079 & 0.044 & $\mathbf{0 . 8 9 2}$ \\
\hline
\end{tabular}

Notes: Rotated components using Varimax; rotation converged in five iterations; Kaiser-Meyer-Olkin measure of sampling adequacy $=0.61$; Bartlett's test of sphericity $=0.001$; loading on dimensions above 0.50 are in bold.

\section{Conclusions}

China and India are striving to meet their growing energy demand by means of exploring both renewable and non-renewable energy options, including imports of fossil fuels from other countries. Although a sizeable population in both the countries depends on biomass sources from forests for meeting their primary energy demand, the modern forest-based bioenergy sector that is visible in Europe and North America has not gained momentum in these two countries. In this context, the study aimed to explore the perceptions of a group of Chinese and Indian SFPs related to the potential benefits and challenges of developing FBPs in the two countries. A total of 110 SFPs participated in the study, all of whom served 
their respective forestry administrations for a considerable number of years, and therefore, their perspectives could be relevant to get a broader picture of the forest-based bioenergy sector in China and India.

In terms of potential benefits from FBPs, the SFPs widely agreed on the economic and ecological benefits from such projects. The two economic benefits from FBPs of job creation and providing additional income to forest departments were the most accepted benefits, while the positive impacts on ecological aspects were also highly acknowledged by them. In this respect, the findings from the study appeared to be similar to the studies from the U.S. and Nepal [18,22]. Apart from the notion of improving forest health through the development of FBPs, the Chinese and Indian SFPs seemed to have large consensus on the positive aspects of developing FBPs in their countries. The SFPs from both countries also widely agreed on some of the potential challenges of developing FBPs in their countries. The lack of availability of suitable technologies and the absence of supportive policies for FBPs emerged as the most commonly agreed upon potential challenges by the SFPs.

The majority of the SFPs agreed on the issues of infrastructure, investment, low public awareness and low public acceptability as the other potential challenges against developing FBPs in their countries. It appeared that on the issue of cost competitiveness of FBPs compared with other renewable energy projects, the SFPs were quite divided in their perceptions. This could be related to the fact that forestbased bioenergy industries are yet to gain momentum in both countries, and therefore, the respondents did not have much information on this cost aspect. Almost one-third of the SFPs also appeared to have no clear position regarding this cost issue, and this perhaps resulted from a non-existent forest-based bioenergy sector in the two countries. A similar type of variation in the perceptions of the SFPs appeared in the issue of their familiarity with developing FBPs. Although slightly over half of the SFPs agreed that they lacked information related to developing FBPs, there was also an equal number of them who either disagreed or remained neutral to that issue. Nevertheless, this indicates that there is a need for improving skills and knowledge regarding FBPs among the interested and motivated forestry professionals working for the state in China and India. The Chinese SFPs were more in agreement with all of the challenges related to developing FBPs in China compared to their Indian counterparts regarding India. Although no apparent reason could be attributed to this difference, this perhaps indicated that the Chinese participants could have more experience with the development of FBPs in their country under the Development Plan for China's Bio-forestry Businesses, which was started in 2007 by their government, and they were responsible for improving public perceptions of FBPs in China [21].

The three key dimensions that emerged from the SFPs' perceptions of FBPs in a way indicated the sustainability aspects of such projects that would need to address the ecological, economic and social dimensions to realize their potential benefits and overcome the challenges before becoming a viable option for China and India. If implemented properly, these can reduce the chances of future conflicts, which have emerged in many parts of the world related to both solid and liquid biofuel projects [27-30]. It has been found that public awareness of bioenergy is lower compared to other renewable energy technologies, such as wind and solar [31], and therefore, overcoming this particular challenge in China and India is a prerequisite for the successful implementation of FBPs. In addition, framing and implementing supportive bioenergy policies in order to improve the competitiveness of the bioenergy sector against other RE technologies and developing modern technology and infrastructure for FBPs, such as CHP (combined heat and power), gasification and liquid biofuels, could establish a viable forest-based bioenergy sector in both China and India. However, in addition to addressing the social and 
economic issues, the development of FBPs must take into account the ecological viability of forests in these two countries, as both are highly rich in biodiversity, and at the same time, they are fragile, due to the negative impacts of the ongoing socio-economic processes.

The study adds to the growing body of literature on experts' perceptions of bioenergy, particularly the option for energy production from forest biomass. The findings from the study to a large extent support previous studies where experts from Europe and the U.S. perceived that bioenergy could provide significant economic benefits, as well as improve energy security; however, technology, infrastructure and public awareness should also be improved to have a viable bioenergy industry [13-19]. Other studies, which were conducted in developing countries, such as Brazil, China and Nepal, also found similar perceptions of bioenergy among their experts [17,20-23]. These findings indicate that the potential benefits and challenges of bioenergy projects, including FBPs, are perhaps similar on a global scale. However, developing countries differ significantly in terms of complex socio-economic conditions from the developed countries. Therefore, at the time of developing bioenergy projects in countries, such as China and India, the country specific socio-economic and ecological issues should be given considerable attention. Without this consideration, it will be difficult for the bioenergy industries in these countries to be viable in the long run.

It is expected that the findings of this study could have some relevancy for the countries that have similar conditions in their forestry sectors, like China and India. From a policy point of view, it could be beneficial to conduct similar studies in those countries to explore the forestry and energy experts' perceptions of FBPs. Such studies could identify the country-specific key factors that could influence the development of FBPs. The present study was limited to the SFPs in China and India, and therefore, future studies should include other expert groups, such as bioenergy researchers, bioenergy industries, civil societies and officials from other government departments, to conduct a broader evaluation of the potentials of the FBPs in China and India.

\section{Acknowledgments}

The author is thankful to the anonymous reviewers for their valuable suggestions and comments, which helped to improve the manuscript substantially. The author acknowledges the contributions of $\mathrm{Qu}$ Mei from Northwest A\&F University, China, for conducting the survey among the Chinese participants and helping with the initial data processing. The author also acknowledges Javier Arevalo from the University of Eastern Finland, Finland, for conducting the survey among the Indian participants in Finland. All of the survey respondents from China and India are thanked by the author. Funding support for language editing from the project, Sustainable Bioenergy Solutions for Tomorrow (BEST) — Case India [Project No. 28303-400/13 BEST-SHOK (Strategic Centres for Science, Technology and Innovation) Metsä], is greatly acknowledged. Finally, a personal research grant from the Kone Foundation (Helsinki, Finland) was instrumental to prepare this article.

\section{Conflicts of Interest}

The author declares no conflict of interest. 


\section{References}

1. International Energy Agency. World Energy Outlook 2012; OECED/IEA: Paris, France, 2012.

2. UNEP Collaborating Centre for Climate \& Sustainable Energy Finance. Global Trends in Renewable Energy Investment 2012; Frankfurt School of Finance \& Management: Frankfurt, Germany, 2012.

3. Qiu, H.; Sun, L.; Huang, J.; Rozelle, S. Liquid biofuels in China: Current status, government policies, and future opportunities and challenges. Renew. Sustain. Energy Rev. 2012, 16, 3095-3104.

4. National Development Reform Commission. Medium- and Long-Term Development Plan for China's Renewable Energy; National Development Reform Commission: Beijing, China, 2007.

5. Ministry of New and Renewable Energy. National Policy on Biofuels; Government of India: New Delhi, India, 2009.

6. Das, S.; Priess, J.A. Zig-zagging into the future: The role of biofuels in India. Biofuels Bioprod. Biorefining 2011, 5, 18-27.

7. Sengupta, M.; Poddar, A. National policy on biofuel under the scanner. Int. J. Emerg. Technol. Adv. Eng. 2013, 3, 521-526.

8. Yang, J.; Dai, G.; Ma, L.; Jia, L.; Jian, W.; Wang, X. Forest-based bioenergy in China: Status, opportunities, and challenges. Renew. Sustain. Energy Rev. 2013, 18, 478-485.

9. Halder, P.; Arevalo, J.; Tahvanainen, L.; Pelkonen, P. Benefits and challenges associated with the development of forest-based bioenergy projects in India: Results from an expert survey. Challenges 2014, 5, 100-111.

10. Aradhey, A. India Biofuels Annual 2012; GAIN Report No. IN2081; USDA Foreign Agricultural Service: New Delhi, India, 2012; pp. 1-16.

11. Garg, K.K.; Karlberg, L.; Wani, S.P.; Berndes, G. Jatropha production on wastelands in India: Opportunities and trade-offs for soil and water management at the watershed scale. Biofuels Bioprod. Biorefining 2011, 5, 410-430.

12. Halder, P.; Arevalo, J.; Mola-Yudego, B.; Gritten, D. Stakeholders' perceptions of bioenergy - Global coverage and policy implications. In Energy Security and Development-The Global Context and Indian Perspectives; Reddy, B.S., Ulgiati, S., Eds.; Springer: Berlin, Germany, 2014; p. 450.

13. Magar, S.B.; Pelkonen, P.; Tahvanainen, L.; Toivonen, R.; Toppinen, A. Growing trade of bioenergy in the EU: Public acceptability, policy harmonization, European standards and certification needs. Biomass Bioenergy 2011, 35, 3318-3327.

14. Hall, J.; Matos, S.; Severino, L.; Beltrão, N. Brazilian biofuels and social exclusion: Established and concentrated ethanol vs. emerging and dispersed biodiesel. J. Clean. Prod. 2009, 17, 77-85.

15. Aguilar, F.; Garrett, H.E. Perspectives of woody biomass for energy: Survey of state foresters, State Energy Biomass Contacts, and National Council of Forestry Association executives. J. For. 2009, 107, 297-306.

16. Stidham, M.; Simon-Brown, V. Stakeholder perspectives on converting forest biomass to energy in Oregon, USA. Biomass Bioenergy 2011, 35, 203-213.

17. Hultman, N.E.; Malone, E.L.; Runci, P.; Carlock, G.; Anderson, K.L. Factors in low-carbon energy transformations: Comparing nuclear and bioenergy in Brazil, Sweden, and the United States. Energy Policy 2012, 40, 131-146. 
18. Dwivedi, P.; Alavalapati, J.R.R. Stakeholders' perceptions on forest biomass-based bioenergy development in the southern US. Energy Policy 2009, 37, 1999-2007.

19. Mayfield, C.A.; Foster, C.D.; Smith, C.T. Opportunities, barriers, and strategies for forest bioenergy and bio-based product development in the Southern United States. Biomass Bioenergy 2007, 31, 631-637.

20. Qu, M.; Ahponen, P.; Tahvanainen, L.; Pelkonen, P. Chinese academic experts' assessment for forest bio-energy development in China. Energy Policy 2010, 38, 6767-6775.

21. Qu, M.; Ahponen, P.; Tahvanainen, L.; Gritten, D.; Mola-Yudego, B.; Pelkonen, P. Practices and perceptions on the development of forest bioenergy in China from participants in national forestry training courses. Biomass Bioenergy 2012, 40, 53-62.

22. Gautam, B.Y.; Halder, P.; Pelkonen, P. Perceptions of bioenergy among Nepalese foresters-Survey results and policy implications. Renew. Energy 2013, 57, 533-538.

23. Ravindranath, N.H.; Sita Lakshmi, C.; Manuvie, R.; Balachandra, P. Biofuel production and implications for land use, food production and environment in India. Energy Policy 2011, 39, 5737-5745.

24. United Nations Economic Commission for Europe (UNECE). The Importance of China's Forest Products Markets to the UNECE Region; Geneva Forest and Timber Discussion Paper 57; United Nations Economic Commission for Europe: Geneva, Switzerland, 2009; pp. 1-26.

25. Nunnaly, J.C. Psychometric Theory; McGraw-Hill: New York, NY, USA, 1978; pp. 1-701.

26. Briggs, S.R.; Cheek, J.M. The role of factor analysis in the evaluation of personality scales. J. Personal. 1986, 54, 106-148.

27. Amigun, B.; Musango, J.K.; Brent, A.C. Community perspectives on the introduction of biodiesel production in the Eastern Cape Province of South Africa. Energy 2011, 36, 2502-2508.

28. Casson, A. The Hesitant Boom: Indonesia's Oil Palm Sub-Sector in an Era of Economic Crisis and Political Change; Occasional Paper No. 29; Centre for International Forestry Research: Bogor, Indonesia, 2000; pp. 1-50.

29. Upham, P.; Shackley, S. Local public opinion of a proposed 21.5 MW(e) biomass gasifier in Devon: Questionnaire survey results. Biomass Bioenergy 2007, 31, 431-441.

30. Wakker, E. Greasy Palms: The Social and Ecological Impacts of Large-Scale Oil Palm Plantation Development in Southeast Asia; Friends of the Earth: London, UK, 2005; pp. 1-54.

31. Energy Technologies: Knowledge, Perceptions, Measures. Available online: http://ec.europa.eu/ public_opinion/archives/ebs/ebs_262_en.pdf (accessed on 20 April 2014).

(C) 2014 by the authors; licensee MDPI, Basel, Switzerland. This article is an open access article distributed under the terms and conditions of the Creative Commons Attribution license (http://creativecommons.org/licenses/by/4.0/). 